\title{
A microbiological study of non-gonococcal proctitis in passive male homosexuals
}

\author{
P. E. MUNDAY*† \\ M.B., M.R.C.O.G. \\ A. P. JOHNSON*
B.Sc., Ph.D. \\ B. J. Thomas* \\ B.Sc., Ph.D. \\ D. J. JEFFRIES§ \\ B.Sc., M.B., M.R.C.Path.
}

\author{
S. G. Dawson $\dagger$ \\ M.B. B.S.
}

M. J. OSBORN*

S. PHILIP $\ddagger$

F.I.M.L.S.

J. R. W. HARRIS $\dagger$

M.R.C.P., D.T.M.\&H.

\section{TAYLOR-ROBINSON* M.D., F.R.C.Path.}

\begin{abstract}
*The Sexually Transmitted Diseases Research Group, MRC Clinical Research Centre, Harrow, $\dagger$ The Praed Street Clinic, St Mary’s Hospital, Paddington, and the Departments of $\ddagger$ Microbiology and §Virology, St Mary’s Hospital Medical School, London
\end{abstract}

\section{Summary}

In a study of 180 male homosexual patients attending a venereal disease clinic, a correlation was sought between symptoms and signs of proctitis and the isolation of Neisseria gonorrhoeae, group B streptococci, Chlamydia trachomatis, Ureaplasma urealyticum, Mycoplasma hominis and herpes simplex virus. Faecal specimens were examined for enteric pathogens and serological tests for hepatitis $B$ virus, syphilitic and chlamydial infections were performed.

There was no association between proctitis, as diagnosed by examination of a Gram-stained rectal smear, and the isolation of any micro-organism or detection of a positive serological test. There was, in addition, no association between any symptom or abnormal physical sign and any positive microbiological findings. Since $23 \%$ of patients from whom $N$. gonorrhoeae was isolated had no abnormal physical signs, it is difficult to assign a pathogenic role to other micro-organisms isolated from patients with and without clinical signs of proctitis. Approaches to further investigation of the problem are discussed.

\section{Introduction}

Neisseria gonorrhoeae is believed to be a pathogen

Address for reprints: Dr P. E. Munday, Division of Communicable Diseases, Clinical Research Centre, Watford Road, Harrow HA1 3UJ, Middlesex. in the rectum producing a proctitis which may or may not be symptomatic (Fluker et al., 1980). Many male homosexuals admitting to passive peno-anal coitus complain of symptoms related to the lower bowel. In addition, asymptomatic patients when examined by proctoscopy may be found to have abnormal signs in the absence of gonococcal infection. The aetiology of these non-gonococcal proctitis (NGP) 'infections' is unknown and the management empirical.

It is reasonable to suppose that NGP might arise from known gastrointestinal pathogens or as a result of infection from organisms transmitted from the active sexual partner. It has been recognized recently that many intestinal pathogens including Giardia lamblia (Meyers, Kuharic and Holmes, 1977), Entamoeba histolytica (Schmerin, Gelston and Jones, 1977), Shigella spp. (Dritz and Back, 1974) and Salmonella spp. (Dritz and Braff, 1977) previously thought to be acquired from infected sources of food and water, may be sexually transmitted. Furthermore, micro-organisms known to be pathogenic or suspected of pathogenicity in the male urethra may be transmitted to the rectum and it is possible that some cause proctitis. Chlamydia trachomatis which appears to cause $50 \%$ of cases of non-gonococcal urethritis (NGU) has been isolated sporadically from the rectum (Darougar et al., 
1972; Goldmeier and Darougar, 1977; McMillan, Sommerville and McKie, 1981) but its association with NGP is unknown. Ureaplasma urealyticum may cause a proportion of cases of NGU and can be isolated from the anal canal of females without difficulty (Munday, Furr and Taylor-Robinson, 1981) but there are no reports of the micro-organism having been isolated from the rectum of male homosexuals. Mycoplasma hominis has been associated with NGU but evidence that it is a pathogen is lacking (Taylor-Robinson and McCormack, 1980). Herpes simplex virus (HSV) undoubtedly may cause a severe proctitis (Curry et al., 1978) associated with a more widespread syndrome of bladder involvement and sensory neurological changes. The sexual transmission of hepatitis B virus (HBV) has been suspected since 1971 (Hersh et al., 1971) and studies of homosexual men have suggested that they have a higher incidence of HBV antigens and antibody than heterosexuals (Szmuness et al., 1975). However, there are no reports of viral proctitis attributed to HBV. Group B streptococci (GBS) have been isolated from the genital tract but the perianal skin has been thought to be the primary site of colonization (Easmon et al., 1981). Faecal carriage of GBS has been recorded (Islam and Thomas, 1980) but it is not known if the rectum is colonized by these organisms and whether they are pathogenic at this site.

In an attempt to establish what role these various micro-organisms play in NGP the authors conducted a prospective study of 180 male homosexual patients attending a large clinic for sexually transmitted diseases in West London.

\section{Patients and methods}

The design of the study was approved by the ethics committee. As far as possible consecutive male patients attending for the first time or previously registered patients who had not attended in the previous month and who admitted to passive peno-anal coitus were selected for study provided that they gave informed consent to participate; had not suffered from ulcerative colitis, Crohn's disease or other intestinal disorder which might affect the rectum; and had not taken antibiotics in the previous month. A full clinical history was taken and each patient was examined by one of the two participating clinicians. The perianal area was inspected and fissures, condylomata, haemorrhoids or other lesions noted. A proctoscope, lubricated with KY jelly was then passed and the rectal mucosa inspected. The presence of erythema, pus, blood, mucus or other abnormality was recorded. Specimens were taken, as described below, before withdrawal of the proctoscope. The findings were recorded on a standardized data sheet.
The following specimens were obtained, using $\stackrel{\mathbb{Q}}{\mathscr{Q}}$ cotton-wool-tipped swabs unless otherwise stated, $C$. in the order indicated: (i) a perianal swab, for $\vec{F}$ isolation of GBS, which was transported in modified $\stackrel{?}{+}$ Ames medium (Transwab: M.W.E. Co., Ltd) to the laboratory; (ii) a rectal wall smear, which was $\frac{\bar{\sigma}}{\bar{\rho}}$ Gram-stained and examined $(\times 800)$ for Gram- $\frac{\sigma}{\sigma}$ negative diplococci and polymorphonuclear leucocy- $\varrho$ tes (PMNL); (iii) a similar specimen for inoculation के on to pre-warmed serum-free Neisseria Isolation $\overrightarrow{0}$ Medium (Difco) for the isolation of N. gonorrhoeae; $;$ (iv) a polyester sponge swab (Oates, Selwyn and $\vec{\omega}$ Breach, 1971) which was agitated in 2SP transport $ᄋ$ medium (Thomas et al., 1977) and this put in liquido nitrogen for transport and storage until tested for $C$. 3 . trachomatis; (v) a swab which was agitated in myco- vy plasma transport medium (Taylor-Robinson et al., 1971) and also stored in liquid nitrogen until tested $\omega$ for $U$. urealyticum and $M$. hominis; (vi) a swab which $\partial े$ was placed in virus transport medium $(0.08 \% \mathcal{G}$ bovine albumin in digest broth) for subsequent $\triangle$ identification of HSV; (vii) a swab from the rectal $\vec{z}$ wall for GBS isolation; and (viii) when possible, a faecal specimen, obtained through the proctoscope $\$$ for identification of enteric bacteria and parasites. $\frac{3}{6}$ A specimen of blood was obtained for serological $\stackrel{\oplus}{\text { - }}$ tests for syphilis, identification of HBV surfage $\overrightarrow{0}$ antigen $\left(\mathrm{HB}_{\mathrm{s}} \mathrm{Ag}\right)$ and chlamydial antibody studies. Finally, the patient was asked to submit 2 or faecal specimens.

\section{Isolation of $\mathrm{N}$. gonorrhoeae}

The inoculated plates were incubated overnight at $\stackrel{\circ}{\varnothing}$ $37^{\circ} \mathrm{C}$ in an atmosphere of $7 \% \mathrm{CO}_{2}$ in air and $90 \%$ humidity. Any oxidase positive, Gram-negative응 cocci were identified by their ability to ferment glucose but not maltose, lactose or sucrose. Negative cultures were re-incubated and re-examined after a further $24 \mathrm{hr}$.

\section{Isolation of $\mathrm{C}$. trachomatis}

Samples were inoculated on to cycloheximide- $\delta$ treated McCoy cells as described previously (Thomas $₹$ et al., 1977) with the modification that the tissue culture medium was supplemented with gentamicin $D$ $(10 \mu \mathrm{g} / \mathrm{ml})$. The cells were stained with Giemsa, and chlamydial inclusions were detected by $\operatorname{dark}_{\bar{N}}$ ground microscopy.

Isolation of $\mathrm{U}$. urealyticum and $\mathrm{M}$. hominis

Samples were thawed rapidly and serial 10 -fold dilutions, up to $10^{-3}$, were made in urea-containinge and arginine-containing mycoplasma liquid media $\mathbb{\complement}$ (Taylor-Robinson et al., 1971). Organisms which $\stackrel{?}{+}$ produced a colour change from yellow to magenta $\frac{T}{T}$ in urea-containing medium were regarded as $U . \stackrel{\mathrm{O}}{\mathbb{D}}$ 
urealyticum while those which hydrolysed arginine were regarded as $M$. hominis

\section{Isolation of group B streptococci}

Swabs were plated on Islam's medium as described previously (Easmon et al., 1981) and swabs and faeces were also passed through a selective ToddHewitt broth as an enrichment medium.

\section{Examination of faecal specimens}

Up to 3 specimens were examined from each patient. Wet preparations were made in normal saline and in iodine and were examined microscopically for ova, cysts and protozoa. The faeces were cultured on desoxycholate-citrate-lactose-sucrose agar (Difco) and Hektoen enteric agar (Difco) for the presence of salmonellae and shigellae; selenite F (Southern Group) was used as an enrichment medium. A modified zinc sulphate flotation technique (Bartlett et al., 1978) was used to concentrate faecal ova and cysts that might not have been seen by direct microscopy.

\section{Isolation of herpes simplex virus}

The specimens were inoculated into Vero cell, Hep-2 cell and human embryo fibroblast cell (MRC-5) cultures which were incubated at $37^{\circ} \mathrm{C}$ and inspected daily for cytopathic effects. Isolates of HSV were typed by inoculation of the chorioallantoic membrane of fertile hens' eggs. The eggs were harvested and inspected for pock morphology after 3 days.

\section{Serological tests for syphilis (STS)}

The Treponema pallidum haemagglutination (TPHA) test (Becton-Dickinsen), the Venereal Disease Research Laboratory (VDRL) test (Wellcome) and, in some cases, the fluorescent treponemal antibody (FTA) test (Fusizoki) were performed. Since a considerable proportion ( $41 \%$ ) of the study population had been treated previously for syphilis, a positive serological test was recorded only when the results had been assessed in the light of the previous history and when the possibility of a biological false positive had been excluded.

\section{Identification of hepatitis $B$ virus}

Serum samples were tested for $\mathrm{HB}_{\mathrm{s}} \mathrm{Ag}$ by direct passive agglutination (Wellcome).

\section{Chlamydial serology}

Chlamydial IgM and IgG antibody to a range of serotypes was sought by a micro-immunofluorescence method (Thomas, Reeve and Oriel, 1976). A positive result was recorded if the titre of IgG antibody was 1 in $\geqslant 16$ or the titre of IgM antibody was 1 in $\geqslant 8$.

\section{Patient groups}

Patients from whom $N$. gonorrhoeae was isolated comprised one group (presumptive gonococcal proctitis). In 13 cases, Gram-negative diplococci were seen in the smear but $N$. gonorrhoeae was not isolated. These smear results were regarded as false positives and the patients allotted to NGP or control groups after review of their smears. Patients from whom $N$. gonorrhoeae was not isolated were divided into 2 groups on the basis of an arbitrary number of PMNL: those with $\geqslant 15$ PMNL/HPF on their Gram-stained smear (NGP group); and those with $<15$ PMNL/HPF (negative control group).

\section{Statistical methods}

All comparisons between groups were made using $\chi^{2}$ tests with Yates' correction except for age, for which Wilcoxon rank sum tests were used.

\section{Results}

\section{Diagnostic categories}

Specimens were obtained from 180 patients. $N$. gonorrhoeae was isolated from 26 patients who comprised the presumptive gonococcal proctitis group. There were $\geqslant 15$ PMNL/HPF on the rectal smears from 51 patients from whom $N$. gonorrhoeae was not isolated (NGP). The negative control group consisted of 87 patients from whom $N$. gonorrhoeae was not isolated and who had no evidence of proctitis (as defined above). In 16 patients, either the Gram-stained smear or the culture for $N$. gonorrhoeae was not available and these patients could not be allotted to a diagnostic category.

A history of contact with urethral gonorrhoea was given by $19(11 \%)$ patients. Six patients $(3 \%)$ and 4 patients $(2 \%)$ had been in contact with a patient suffering from NGU or unspecified urethritis respectively.

\section{Microbiological findings}

The distribution of micro-organisms and the serological findings in the designated groups of patients are shown in Table 1. The micro-organisms most commonly isolated were $U$. urealyticum $(34 \%)$ and $M$. hominis $(34 \%)$. One or both of these micro-organisms was isolated from $75 / 165$ patients $(45 \%)$. GBS were isolated from the rectum of $22 \%$ of patients. C. trachomatis and HSV were identified in $6 \%$ and $5 \%$ of patients respectively. $\mathrm{HB}_{\mathrm{s}} \mathrm{AG}$ was detected in the serum of $3 \%$ of patients and in $7 \%$ there was serological evidence of previously undiagnosed syphilis. Stool specimens were obtained from 127 patients $(71 \%)$ only. G. lamblia was isolated from $3 \%$ of these patients and Enterobius vermicularis from $2 \%$. In $18 \%$ of patients, nonpathogenic amoebae were identified. 
TABLE 1. Prevalence of each micro-organism and microbiological findings in the designated study groups

\begin{tabular}{|c|c|c|c|c|c|}
\hline $\begin{array}{l}\text { Micro-organism or } \\
\text { serological finding }\end{array}$ & $\begin{array}{l}\text { Presumptive } \\
\text { gonococcal } \\
\text { proctitis }\end{array}$ & $\begin{array}{l}\text { Non-gonococcal } \\
\text { proctitis }\end{array}$ & Control & Other & Total \\
\hline $\begin{array}{l}\text { Neisseria gonorrhoeae } \\
\text { Group B streptococci: }\end{array}$ & *26/26 & $0 / 51$ & $0 / 87$ & $0 / 7$ & 26 \\
\hline -perianal skin & $8 / 25$ & $12 / 48$ & $22 / 86$ & $2 / 16$ & 44 \\
\hline -rectum & $4 / 15$ & $7 / 40$ & $13 / 58$ & $3 / 10$ & 27 \\
\hline -faeces & $1 / 18$ & $1 / 36$ & $5 / 66$ & $0 / 7$ & 7 \\
\hline Chlamydia trachomatis & $4 / 26$ & $3 / 51$ & $3 / 83$ & $0 / 16$ & 10 \\
\hline Ureaplasma urealyticum & $11 / 24$ & $20 / 49$ & $23 / 81$ & $1 / 7$ & 55 \\
\hline Mycoplasma hominis & $11 / 25$ & $19 / 49$ & $22 / 79$ & $3 / 7$ & 55 \\
\hline Herpes simplex virus & $2 / 24$ & $1 / 46$ & $3 / 85$ & $3 / 14$ & 9 \\
\hline Giardia lamblia & $0_{1}$ & 0 & 3 & 1 & 4 \\
\hline Entamoeba histolytica & 0 & 0 & 0 & 0 & 0 \\
\hline Ent. coli & $4 \succ / 18$ & $3\} / 36$ & $10\} / 66$ & $2 \succ 17$ & 19 \\
\hline Enterobius vermicularis & 1 & 0 & 1 & 0 & 2 \\
\hline E. buetchlii & 1 & $0^{\prime}$ & 2) & 1 & 4 \\
\hline $\mathrm{HB}_{\mathrm{S}} \mathrm{Ag}$ positive & $1 / 26$ & $2 / 51$ & $0 / 86$ & $2 / 15$ & 5 \\
\hline $\begin{array}{l}\text { Serological test for syphilis } \\
\text { positive }\end{array}$ & & & & & \\
\hline $\begin{array}{l}\text { positive } \\
\text { C. } \text { trachomatis } \text { IgG antibody }\end{array}$ & $\begin{array}{l}3 / 25 \\
6 / 22\end{array}$ & $\begin{array}{r}4 / 50 \\
10 / 40\end{array}$ & $\begin{array}{r}4 / 84 \\
21 / 78\end{array}$ & $\begin{array}{l}1 / 16 \\
1 / 6\end{array}$ & $\begin{array}{l}12 \\
38\end{array}$ \\
\hline IgM antibody & $3 / 21$ & $5 / 39$ & $11 / 77$ & $0 / 6$ & 19 \\
\hline
\end{tabular}

*number of patients positive/number of patients tested.

More than one micro-organism was isolated from most patients. One patient, for example, had positive serological tests for syphilis and $N$. gonorrhoeae, $C$. trachomatis, $M$. hominis and $U$. urealyticum were isolated from his rectum. Two patients who had HSV infections also had detectable $\mathrm{HB}_{\mathbf{s}} \mathrm{Ag}$.

Overall, one or more micro-organisms were isolated from, or abnormal serological tests detected in, 134 patients $(74 \%)$. However, in only 53 patients $(29 \%)$ was a recognized pathogen (i.e. $N$. gonorrhoeae, $C$. trachomatis, $H$. simplex, $G$. lamblia or E. vermicularis) isolated or $\mathrm{HB}_{\mathrm{s}} \mathrm{Ag}$ or positive STS detected.

\section{Microbiological findings in relation to diagnostic category}

When the prevalence of each micro-organism or serological finding in the various diagnostic categories was considered, no micro-organism or abnormal serological result was found to occur significantly more often in one diagnostic category than in another. Similarly, there was no difference in the prevalence of the various findings, if those patients who were smear-positive but culturenegative for $N$. gonorrhoeae were classified as having gonococcal infections. When the microbiological and serological findings for the patients with presumptive gonococcal proctitis and NGP together were compared with those for the negative control group, there was still no significant difference between them. However, the prevalence of all the micro-organisms and abnormal serological findings was greater in the presumptive gonococcal proctitis group than in the other 2 groups. The prevalence of the micro-organisms and serological findings in the NGP and negative control groups was similar except for the more frequent occurrence of $U$. urealyticum and $M$. hominis in the NGP group.

Microbiological findings in relation to symptoms and signs

There was no association between the microbiological findings and any symptom or sign (Table 2). It should be noted that $38 \%$ of patients with gonorrhoea were asymptomatic and $23 \%$ had no abnormal physical signs. The corresponding figures for $C$. trachomatis were $50 \%$ and $30 \%$, for HSV $56 \%$ and $33 \%$, for $U$. urealyticum $44 \%$ and $38 \%$, and for $M$. hominis $36 \%$ and $31 \%$.

\section{Population differences}

In order to assess whether the prevalence of microorganisms or abnormal clinical findings might be influenced by differences in the populations studied, the groups were compared with regard to age, race, country of origin, travel history, history of previous sexually transmitted disease, and number of recent sexual contacts (as an index of promiscuity). The patients with presumptive gonococcal proctitis were significantly younger $(P=0.04)$ than those with 
TABLE 2. Association of specific micro-organisms and microbiological findings with symptoms and signs of proctitis

\begin{tabular}{|c|c|c|c|c|c|c|c|c|}
\hline $\begin{array}{l}\text { eisseria } \\
\text { gonor- } \\
\text { hoeaee } \\
(26)^{*}\end{array}$ & $\begin{array}{c}\text { Chlamydia } \\
\text { tracho- } \\
\text { matis } \\
(10)\end{array}$ & (9) & $\begin{array}{c}\text { Ureaplasma } \\
\text { urea- } \\
\text { lyticum } \\
(55)\end{array}$ & $\begin{array}{c}\text { Mycoplasma } \\
\text { hominis } \\
\\
\text { (55) }\end{array}$ & $\mathrm{HB}_{\mathrm{s}} \mathrm{Ag}$ & STS + & $\begin{array}{c}\text { Giardia } \\
\text { lamblia } \\
\text { (4) }\end{array}$ & $\begin{array}{l}\text { Enterobius } \\
\text { vermi- } \\
\text { cularis } \\
\text { (2) }\end{array}$ \\
\hline
\end{tabular}

Symptom

Discharge

Pruritus

Bleeding

Pain

Mucus/pus in stool

Change in bowel habit

Urinary abnormality

No symptoms

Sign

Redness

Pus

Mucus

Blood

Bleeding on examination

'Corrugated' appearance

No signs

3
10
3
7
7
10
1
10
11
9
9
1
10
1
6

$\begin{array}{rrrr}0 & 3 & 5 & 4 \\ 5 & 2 & 17 & 24 \\ 2 & 0 & 8 & 9 \\ 1 & 2 & 11 & 14 \\ 2 & 1 & 11 & 11 \\ 1 & 2 & 13 & 15 \\ 0 & 0 & 1 & 1 \\ 5 & 5 & 24 & 20 \\ & & & \\ 6 & 5 & 18 & 21 \\ 3 & 2 & 13 & 11 \\ 2 & 4 & 13 & 14 \\ 1 & 0 & 1 & 0 \\ 3 & 5 & 16 & 19 \\ 0 & 0 & 2 & 2 \\ 3 & 3 & 21 & 17\end{array}$

4
24
9
14
11
15
1
20
21
11
14
0
19
2
17

$\begin{array}{llll}1 & 2 & 0 & 2 \\ 3 & 3 & 1 & 2 \\ 2 & 2 & 0 & 0 \\ 2 & 1 & 0 & 1 \\ 1 & 3 & 0 & 1 \\ 3 & 3 & 1 & 2 \\ 0 & 1 & 0 & 1 \\ 1 & 7 & 3 & 0 \\ 3 & 7 & 2 & 1 \\ 4 & 2 & 0 & 1 \\ 4 & 3 & 2 & 1 \\ 0 & 0 & 0 & 0 \\ 3 & 4 & 1 & 0 \\ 0 & 2 & 1 & 0 \\ 1 & 4 & 0 & 0\end{array}$

*In parentheses: total no. of patients with indicated micro-organism. $\mathrm{HSV}=$ herpes simplex virus; $\mathrm{HB}_{\mathrm{s}} \mathrm{Ag}=\mathrm{hepatitis} \mathrm{B}$ virus surface antigen; $\mathbf{S T S}=$ serological tests for syphilis.

NGP but there were no other differences and, in particular, no differences in promiscuity or a history of gonorrhoea, syphilis or non-gonococcal infection.

Eighteen patients admitted to potentially traumatic activities (fist fornication and related practices). Ten of these patients had proctitis (3 gonococcal) and 8 were in the negative control group.

\section{Discussion}

The criteria for the diagnosis of NGP are unclear and some clinicians do not even recognize it as a disease entity (Adler, 1978). There seems little doubt, however, that some passive homosexuals complain of symptoms related to the rectum and have abnormal physical signs in the absence of gonococcal infection. While traumatic practices may account for a proportion, it is likely that the majority of cases is due to an infective agent or agents.

Notwithstanding sampling problems and the poor quality of some Gram-stained rectal smears, the authors have chosen to define NGP in terms of the number of PMNL/HPF because a degree of objectivity is possible. This approach has meant that a proportion (14\%) of patients with neither symptoms nor gross physical signs has been included in the NGP group. Whether the presence of PMNL in a rectal smear in the absence of any symptoms or signs should be regarded as proctitis is open to question. This question may be resolved only, perhaps, by exploring the relationship between the presence of PMNL, physical signs and the results of rectal biopsy. The latter procedure is difficult to undertake in a very busy clinic and, furthermore, cannot be a substitute for a rectal smear since an immediate presumptive diagnosis is essential for patient management. However, it may be necessary on a research basis. Although it is evident that there is a diagnostic problem, it must be pointed out that the presence of PMNL in a urethral smear in the absence of urethral symptoms or signs would undoubtedly be regarded as evidence of urethritis. A small proportion $(3 \%)$ of patients with gross physical signs of proctitis was included in the negative control group because PMNL were not found in the rectal smear, presumably owing to sampling errors.

C. trachomatis is responsible for approximately $50 \%$ of cases of NGU including a proportion in homosexual men (Munday et al., 1981), so that the rectum would be expected to be a reservoir of infection. The low frequency of infection $(6 \%)$ recorded in this study may reflect, therefore, the small proportion of men (3\%) known to be contacts of patients with NGU and the reluctance to trace contacts of such patients. The prevalence rate for chlamydial IgG and IgM antibody is difficult to interpret without knowledge of the frequency of isolation of chlamydiae from the urethras of these patients; however, the relatively low prevalence $(26 \% \mathrm{IgG} ; 13 \%$ IgM) of antibody in a high risk population (Wang et al., 1975) suggests that $C$. trachomatis infection may be less common among homosexuals than among heterosexuals. Of the 6 chlamydia-positive patients who did not have rectal gonorrhoea, one had severe proctitis, 2 had mild proctitis and 3 had no symptoms or signs of 
disease, so that the results do not provide evidence that this micro-organism is invariably pathogenic in the rectum.

The isolation of HSV from the rectum was also an infrequent occurrence; in only 3 patients $(33 \%)$ was the diagnosis suspected clinically and the complete absence of symptoms or signs in 3 others was surprising. While HSV can cause a severe proctitis (Curry et al., 1978), it seems unlikely that it is responsible for a significant proportion of cases and screening on a routine basis is unlikely to be a costeffective procedure.

Ureaplasmas and $M$. hominis were isolated frequently and, although they were more prevalent in patients with proctitis than in negative control patients, there was no association of either microorganism with any combination of symptoms or signs. This seems to be similar to findings in studies of the male urethra and the female genital tract (Taylor-Robinson and McCormack, 1980). In these studies it has been shown that the prevalence of mycoplasmas is related to promiscuity as measured by the number of sexual partners (McCormack, Lee and Zinner, 1973) but the isolation of mycoplasmas from the rectum was not related to the number of partners in the previous 28 days. It is possible, therefore, that mycoplasmas may be implicated in a proportion of cases of proctitis but further studies would be necessary to confirm this.

There are several descriptions of the sexual transmission of gastrointestinal pathogens (Meyers et al., 1977; Schmerin et al., 1977; Dritz and Back, 1974; Dritz and Braff, 1977), but few surveys of sexually transmitted disease clinic populations have been undertaken, and none in the United Kingdom. Although specimens were not obtained in ideal circumstances and, therefore, the prevalence rates probably represent the minimum, it is apparent that enteric pathogens may be found in the male homosexual population in London. In a previous study at the same clinic (Dawson, Boldy and Harris, unpublished observations), G. lamblia was isolated from the stools of 16 of 50 selected symptomatic patients and $E$. histolytica from 3 of these patients. The low prevalence in the current study, indicates that it is unlikely that these organisms are responsible for a significant proportion of cases of NGP.

Five patients $(3 \%)$ were found to be $\mathrm{HB}_{\mathrm{s}} \mathrm{Ag}$ positive, a figure compatible with those of other studies (Jeffries et al., 1973; Lim et al., 1977). Although proctitis is not a reported manifestation of hepatitis B virus infection, it is believed that the presence of proctitis might predispose to the infection, especially as the virus may be found in semen. Of the 5 patients in the present study, one had gonococcal proctitis, 2 had herpetic proctitis and 2 had non-specific proctitis.
Group B streptococci were found frequently $\stackrel{\mathbb{Q}}{\stackrel{2}{2}}$ $(22 \%)$ in the rectum but there was no evidence that $C$. they were pathogenic at this site and their presence $\overrightarrow{\vec{A}}$ probably represents spread from the primary site of colonization, the perianal skin (Easmon et al., 등 1981).

It has, therefore, not been possible to establish $\frac{\bar{क}}{\bar{\sigma}}$ that NGP, as defined in this study, was caused by $\cong$ any of the recognized pathogens. Indeed, there is a further dilemma in that the isolation of gonococci $\vec{\circ}$ was not associated specifically with the occurrence of proctitis and hence the present use of the term $\vec{\omega}$ 'presumptive gonococcal proctitis'. If it is not $\frac{\Omega}{\circ}$ possible to implicate this micro-organism in disease $\frac{O}{3}$ by a conventional comparative procedure, it is understandable that there are difficulties in establish- -9 ing the role of other micro-organisms. It is possible that gonococci are sometimes carried without $\omega$ causing disease, as in the urethra (Handsfield et al., $\stackrel{\supset}{ }$ 1974) or, alternatively, those carrying them would eventually develop disease if they remained un- $\supset$ treated. It follows, therefore, that the isolation of $\vec{z}$ gonococci at a particular moment in the absence of disease may not necessarily indicate that they are $\stackrel{\Phi}{3}$ not the cause of proctitis when isolated from the $\frac{3}{0}$ rectum of patients with this condition. The same argument may be used, of course, for other micre $\overrightarrow{0}$ organisms. How then might it be possible to establish ${ }_{-\infty}$ the role of gonococci and other micro-organisms:The most profitable lines of approach seem to be to (a) define the means of diagnosing proctitis more accurately so that the association of micro-organisms with disease may be placed on a firmer footing; (b) $\frac{\mathrm{Q}}{\varnothing}$ improve techniques of sampling and undertake $\varrho$ repeat sampling to ensure that the maximum oppor- $\overrightarrow{\overrightarrow{0}}$ tunity for isolating potentially pathogenic micro- 3 organisms has been achieved; and (c) determine whether chemotherapeutic agents which have an effect upon the micro-organisms in vitro are success- $\bar{O}$ ful in treating the disease, an approach analogous to that used for establishing the role of chlamydiae $\frac{5}{3}$ and ureaplasmas in NGU (Taylor-Robinson and Thomas, 1980; Taylor-Robinson and McCormack, 웅 1980). Whether there is a need to seek other microorganisms as a cause of proctitis will depend on 9 the outcome of such investigations. Whatever the $\frac{D}{0}$ outcome, it is clear that micro-organisms which cause disease at anatomical sites other than the $N$ rectum, may be isolated from the rectum without there being any evidence of disease.

\section{Acknowledgments}

We wish to thank Dr G. W. Csonka for access to patients under his care, Dr C. S. F. Easmon for helpful discussion, $\bar{\Phi}$ Miss A. Tanna and Miss P. M. Furr for technical help and $\stackrel{\oplus}{+}$ Mr D. G. Altman for the statistical analyses. We acknow- 7 ledge also the co-operation of the staff of the Praed Street Clinic. 


\section{References}

AdLer, M.W. (1978) Diagnostic, treatment and reporting criteria for non-specific genital infection in sexually transmitted disease clinics in England and Wales: 1. Diagnosis. British Journal of Venereal Diseases, 54, 422.

Bartlett, M.S., Harper, K., Smith, N., Verbanac, P. \& SMITH, J.W. (1978) Comparative evaluation of a modified zinc sulfate flotation technique. Journal of Clinical Microbiology, 7, 524.

Curry, J.P., Embil, J.A., Williams, C.N. \& Manuel, F.R. (1978) Proctitis associated with Herpesvirus hominis type 2 infection. Canadian Medical Association Journal, 119, 485.

Darougar, S., Jones, B.R., Kinnison, J.R., VaughanJACKSON, J.D. \& DunLOP, E.M.C. (1972) Chlamydial infection: Advances in the diagnostic isolation of Chlamydia, including TRIC agent, from the eye, genital tract and rectum. British Journal of Venereal Diseases, 48, 416.

DrITZ, S.K. \& BACK, A.F. (1974) Shigella enteritis venereally transmitted. New England Journal of Medicine, 291, 1194.

DrITZ, S.K. \& BRAFF, E.H. (1977) Sexually transmitted typhoid fever. New England Journal of Medicine, 296, 1359.

Easmon, C.S.F., Tanna, A., Munday, P. \& Dawson, S. (1981) Group B streptococci-gastrointestinal organisms? Journal of Clinical Pathology, 34, 921.

Fluker, J.L., Deherogoda, P., Platt, D.J. \& Gerken, A. (1980) Rectal gonorrhoea in male homosexuals: presentation and therapy. British Journal of Venereal Diseases. 56, 397.

GoldmeIer, D. \& DarougaR, S. (1977) Isolation of Chlamydia trachomatis from throat and rectum of homosexual men. British Journal of Venereal Diseases, 53, 184.

Handsfield, H.H., Lipman, T.O., HaRnisch, J.P., Tronca, E. \& Holmes, K.K. (1974) Asymptomatic gonorrhea in men. Diagnosis, natural course, prevalence and significance. New England Journal of Medicine, 290, 117.

Hersh, T., Melnick, J.L., Goyal, R.K. \& Hollinger, F.B. (1971) Non-parenteral transmission of viral hepatitis type B (Australia antigen-associated serum hepatitis). New England Journal of Medicine, 285, 1363.

IsLAM, A. \& Thomas, E. (1980) Faecal carriage of Group B streptococci. Journal of Clinical Pathology, 33, 1006.

JefFries, D.J., James, W.H., JefFeriss, F.J.G., MACLeOd, K.G. \& Willcox, R.R. (1973) Australia (hepatitisassociated) antigen in patients attending a venereal disease clinic. British Medical Journal, 2, 455.

Lim, K.S., Wong, V.T., Fulford, K.W.M., Catterall, R.D., BRiggs, M. \& DANE, D.S. (1977) Role of sexual and non-sexual practices in the transmission of hepatitis $B$. British Journal of Venereal Diseases, 53, 190.

McCormacK, W.M., LeE, Y-H \& ZinNer, S.H. (1973) Sexual experience and urethral colonization with genital mycoplasmas. A study in normal men. Annals of Internal Medicine, 78, 696.

McMillan, A., Sommerville, R.G. \& McKie, P.M.K. (1981) Chlamydial infection in homosexual men: frequency of isolation of Chlamydia trachomatis from the urethra, ano-rectum and pharynx. British Journal of Venereal Diseases, 57, 47.

MeYers, J.D., Kuharic, H.A. \& Holmes, K.K. (1977) Giardia lamblia infection in homosexual men. British Journal of Venereal Diseases, 53, 54.

Munday, P.E., FurR, P.M. \& TAYlor-Robinson, D. (1981) The prevalence of Ureaplasma urealyticum and Mycoplasma hominis in the cervix and anal canal of women. Journal of Infection, 3, 253.

Munday, P.E., Thomas, B.J., Johnson, A.P., Altman, D.G. \& TAYLOR-Robinson, D. (1981) A clinical and microbiological study of non-gonococcal urethritis with particular reference to non-chlamydial disease. British Journal of Venereal Diseases, 57, 327.

Oates, J.K., Selwyn, S. \& Breach, M.R. (1971) Polyester sponge swabs to facilitate examination for genital infection in women. British Journal of Venereal Diseases, 47, 289.

Schmerin, M.J., Gelston, A. \& Jones, T.C. (1977) Amebiasis-an increasing problem among homosexuals in New York City. Journal of the American Medical Association, 238, 1386.

Szmuness, W., Much, M.I., Prince, A.M., Hoofnagle, J.H., Cherubin, C.E., Harley, E.J. \& Block, G.H. (1975) On the role of sexual behaviour in the spread of hepatitis B infection. Annals of Internal Medicine, 83, 489.

TAYLOR-Robinson, D. \& MCCormaCK, W.M. (1980) The genital mycoplasmas. New England Journal of Medicine. 302, 1003, 1063.

Taylor-Robinson, D., Martin-Bourgon, C., Watanabe, T. \& ADDEY, J.P. (1971) Isolation of T-mycoplasmas from dogs and squirrel monkeys: biological and serological comparison with those isolated from man and cattle. Journal of General Microbiology, 68, 97.

TAYloR-Robinson, D. \& Thomas, B.J. (1980) The role of Chlamydia trachomatis in genital-tract and associated diseases. Journal of Clinical Pathology, 33, 205.

Thomas, B.J., Evans, R.T., Hutchinson, G.R. \& TaylorRobinson, D. (1977) Early detection of chlamydial inclusions combining the use of cycloheximide-treated McCoy cells and immunofluorescence staining. Journal of Clinical Microbiology, 6, 285.

Thomas, B.J., ReEVe, P. \& ORIEL, J.D. (1976) Simplified serological test for antibodies to Chlamydia trachomatis. Journal of Clinical Microbiology, 4, 6.

Wang, S.-P., Grayston, J.T., Alexander, E.R. \& Holmes, K.K. (1975) Simplified microimmunofluorescence test with trachoma-lymphogranuloma venereum (Chlamydia trachomatis) antigens for use as a screening test for antibody. Journal of Clinical Microbiology, 1, 250. 